\title{
Influence of dynamic preoperative body mass index changes on patient-reported outcomes after surgery for degenerative lumbar spine disease
}

\author{
Alessandro Siccoli $^{1,2}$ • Marc L. Schröder ${ }^{1} \cdot$ Victor E. Staartjes $^{1,3,4}$ (D) \\ Received: 28 August 2020 / Revised: 3 November 2020 / Accepted: 2 December 2020 / Published online: 11 December 2020 \\ (C) The Author(s) 2020, corrected publication 2021
}

\begin{abstract}
Psychological factors demonstrably and often massively influence outcomes of degenerative spine surgery, and one could hypothesize that preoperative weight loss may correlate with motivation and lifestyle adjustment, thus leading to potentially enhanced outcomes. We aimed to evaluate the effect of preoperative weight loss or gain, respectively, on patient-reported outcomes after lumbar spine surgery. Weight loss was defined as a BMI decrease of $\leq-0.5 \mathrm{~kg} / \mathrm{m}^{2}$ over a period of at least 1 month, and weight gain as a BMI increase of $\geq 0.5 \mathrm{~kg} / \mathrm{m}^{2}$ in the same time period, respectively. The primary endpoint was set as the achievement of the minimum clinically important difference (MCID) in the ODI at 1 or 2 years postoperatively. A total of 154 patients were included. Weight loss (odds ratio (OR): $1.18,95 \%$ confidence interval (CI): 0.52 to 2.80 ) and weight gain (OR: $1.03,95 \%$ CI: 0.43 to 2.55 ) showed no significant influence on MCID achievement for ODI compared to a stable BMI. The same results were observed when analysing longterm NRS-BP and NRS-LP. Regression analysis showed no correlation between BMI change and PROM change scores for any of the three PROMs. Adjustment for age and gender did not alter results. Our findings suggest that both preoperative weight loss and weight gain may have no measurable effect on long-term postoperative outcome compared to a stable BMI. Weight loss preoperatively-as a potential surrogate sign of patient motivation and lifestyle change - may thus not influence postoperative outcomes.
\end{abstract}

Keywords Obesity · Overweight · Weight loss · Weight gain · Outcome

\section{Introduction}

Obesity is well known to be an independent risk factor for several comorbidities such as cardiovascular diseases or hypertension [24, 34]. Additionally, current literature suggests that obesity actively contributes to low back pain $[11,21,42$, 54], due to the effect of excessive weight on the lumbar spine,

This research has never previously been submitted for review or presented at any conferences

Victor E. Staartjes

victor.staartjes@gmail.com

1 Department of Neurosurgery, Bergman Clinics, Amsterdam, The Netherlands

2 Faculty of Medicine, University of Zurich, Zurich, Switzerland

3 Department of Neurosurgery, Clinical Neuroscience Center, University Hospital Zurich, University of Zurich,

Zurich, Switzerland

4 Bergman Clinics, Naarden, Rijksweg 69, 1411, GE Naarden, The Netherlands and thus consequently leads to a higher probability for that particular patient subpopulation to undergo lumbar spinal surgery [32]. The National Surgery Quality Improvement Program (NSQIP) database already stated that $44 \%$ of patients in a lumbar spine surgery cohort between 2005 and 2010 were obese [8], with an increasing tendency nowadays [1].

The effect of obesity on surgical outcome and complication rate has been well-investigated, with many studies identifying higher intraoperative and postoperative complication rates for obese patients $[7,12,18,33,35]$. This effect is first of all given by the higher prevalence of comorbidities, as well as post-surgical restricted activity $[5,10]$. However, obesity itself also has an important effect on surgical outcome, possibly due to the higher mechanical load on the spine and therefore the surgical site [26]. Thirdly, there might be relevant biopsychosocial factors [13], as obesity has been shown to be a risk factor for depression [17], which itself is known to have an important impact on surgical outcome [9, 16, 45, 52].

However, the effect of weight on the surgical outcome is only well understood as a static value, whereas the effect of weight change prior to surgery remains unclear. In lumbar 
spine surgery, the effect of preoperative weight loss remains uncharted. As a result, studies analysing preoperative weight loss prior to lumbar spine surgery and its clinical effects have been called for $[2,21]$.

Nowadays, it is the general advice for overweight patients to lose weight prior to surgery, as these might profit from reduced mechanical stress and therefore higher chances for positive outcome $[6,23]$. There may also be a psychological effect: Patients willing and able to lose weight prior to surgery may be more motivated for surgery and for post-surgical activity and may thus be hypothesized to experience enhanced outcomes [6]. Similarly, those patients who are motivated to lose weight preoperatively could be suffering from higher amounts of pain, thus potentially increasing likelihood of achieving a clinically important improvement.[4, 50]

The aim of this study is to determine the effect of dynamic weight loss or weight gain on surgical outcome in lumbar spine surgery, specifically on patient-reported outcome measures (PROMs).

\section{Materials and methods}

\section{Design}

From a prospective institutional registry of a single Dutch short-stay spine centre, all patients undergoing lumbar spine surgery between December 2010 and November 2019 were identified. All surgical procedures were performed by a single senior neurosurgeon (M.L.S.) as described previously [ 43,47 , $48,51,53]$. Due to local restrictive regulations by insurance companies, patients aged $>80$ or with a body mass index $(\mathrm{BMI})>33$ or American Society of Anaesthesiologists (ASA) score $>2$ cannot be considered for elective short-stay spine surgery [49]. We included only patients with complete BMI data as defined below, as well as complete baseline and 12-month or 24-month (i.e. long-term) PROMs, and without prior spine surgery at the index level [46].

\section{Ethical considerations}

This registry was approved by the local institutional review board (Medical Research Ethics Committees United, Registration Number: W16.065). The study was performed according to the 2013 Declaration of Helsinki and its later amendments, and all patients provided written informed consent.

\section{Data collection}

All surgical data and patient characteristics were systematically collected in a prospective registry. For all patients included in the study, weight and height were measured at the first preoperative visit and just before surgery. Patients were not informed about this study either pre- or postoperatively. To exclude short-term weight fluctuations, we included only patient with a minimum gap of 1 month between the first and the directly preoperative weight measurement, and BMI change was defined as a minimal difference of $\geq 0.5 \mathrm{~kg} / \mathrm{m}^{2}$. All included patients were divided into 3 groups: Patients with a BMI decrease of $-\geq 0.5 \mathrm{~kg} / \mathrm{m}^{2}$, those with a stable BMI, and those with a BMI increase of $+\geq 0.5 \mathrm{~kg} / \mathrm{m}^{2}$. For baseline PROM assessment, all patients included completed a standardized questionnaire including a validated Dutch version of the Oswestry Disability Index (ODI) as a measure of functional disability, as well as a numeric rating scale (NRS) for leg pain and back pain severity [39]. Follow-up questionnaires with the same PROMs were automatically dispatched via email using a validated follow-up system at 12 months and 24 months after surgery $[39,40]$. If both 12- and 24-month PROMs were available for the same patient, the longer-term outcome was used in the statistical analysis [46].

\section{Statistical analysis}

Categorical data are given as numbers (percentages) and continuous data as mean \pm standard deviation.

The minimal clinically important difference (MCID), therefore clinical success, was set as $\geq 30 \%$ improvement [31] at 12-month or 24-month follow-up for ODI, or for NRS leg pain and NRS back pain, as both endpoints were shown to accurately reflect the other [46]. The primary endpoint of this study was long-term MCID in the ODI. For determining intergroup differences in MCID achievement, we conducted univariate logistic regression, where the patients with a stable BMI are defined as reference group, and additionally a multivariate logistic regression analysis adjusted for age and gender [44]. We also carried out univariate linear regression to evaluate the linear relationship between BMI change score and PROM change score and used multivariate linear regression for age and gender adjustment. All analyses were carried out using R Version 3.6.1 (The R Foundation for Statistical Computing, Vienna, Austria) [36]. A 2-tailed $p \leq 0.05$ was considered statistically significant.

\section{Results}

\section{Overview}

Baseline characteristics along with surgical indications and baseline PROMs are reported in Table 1. In our prospective registry, 154 patients underwent lumbar spine surgery for degenerative disease and had complete PROM data and two different BMI values with at least a 1-month interval [40]. Most patients (87 pts., 56\%) underwent tubular 
microdiscectomy, while 35 patients $(23 \%)$ underwent decompression and interbody fusion and $32(21 \%)$ underwent decompression only. We observed $40(26 \%)$ patients with weight loss, $81(53 \%)$ patients with stable BMI, and 33 (21\%) patients with weight gain. The average BMI difference was $-0.18 \pm 1.13 \mathrm{~kg} / \mathrm{m}^{2}$, and mean inter-measurement interval was $121 \pm 98$ days. A bar and density plot with a corresponding box plot of the BMI change distribution is given in Fig. 1. Overall MCID achievement at long-term follow-up was $70.1 \%$ for ODI, $70.1 \%$ for NRS leg pain severity, and $61.0 \%$ for NRS back pain severity. The achievement rates for every BMI subgroup are shown in Fig. 2.

\section{Logistic regression}

All results of the logistic regression are shown in Table 2. Compared to the patients with a stable BMI, weight loss $(\mathrm{OR}=1.177,95 \% \mathrm{CI}=0.516-2.797)$ or weight gain $(\mathrm{OR}=$

Table 1 Baseline patient characteristics

\begin{tabular}{|c|c|}
\hline Characteristic & Value \\
\hline Age & $53.0 \pm 11.9$ \\
\hline Active smoker & $46(31 \%)$ \\
\hline BMI $\left(\mathrm{kg} / \mathrm{m}^{2}\right)$ & $26.2 \pm 3.4$ \\
\hline \multicolumn{2}{|l|}{ Indication } \\
\hline $\mathrm{LDH}$ & $87(56 \%)$ \\
\hline Lumbar stenosis & $32(21 \%)$ \\
\hline DDD & $19(12 \%)$ \\
\hline Spondylolisthesis & $16(10 \%)$ \\
\hline \multicolumn{2}{|l|}{ Surgical technique } \\
\hline Microdiscectomy & $87(56 \%)$ \\
\hline Decompression and fusion & $35(23 \%)$ \\
\hline Decompression & $32(21 \%)$ \\
\hline \multicolumn{2}{|l|}{ ASA score } \\
\hline Class I & $72(48 \%)$ \\
\hline Class II & $77(52 \%)$ \\
\hline \multicolumn{2}{|l|}{ Index level } \\
\hline L1-L2 & $2(1.3 \%)$ \\
\hline L2-L3 & $4(2.6 \%)$ \\
\hline L3-L4 & $19(12 \%)$ \\
\hline L4-L5 & $83(54 \%)$ \\
\hline L5-S1 & $46(30 \%)$ \\
\hline Baseline ODI & $44.5 \pm 17.2$ \\
\hline Baseline NRS leg & $6.7 \pm 2.4$ \\
\hline Baseline NRS back & $6.2 \pm 2.5$ \\
\hline Mean BMI change score & $-0.18 \pm 1.13$ \\
\hline Mean BMI measurement interval & $121 \pm 98$ \\
\hline
\end{tabular}

BMI, body mass index; LDH, lumbar disc herniation; DDD, degenerative disc disease; ASA, American Society of Anesthesiologists; ODI, Oswestry Disability Index, NRS, numeric rating scale
$1.027,95 \% \mathrm{CI}=0.432-2.548$ ) showed no statistical difference in MCID achievement for ODI - the primary endpoint. Regarding MCID for leg pain severity, the decrease in BMI $(\mathrm{OR}=1.190,95 \% \mathrm{CI}=0.511-2.912)$ or increase in BMI (OR $=0.610,95 \% \mathrm{CI}=0.261-1.443$ ) showed no difference compared to a stable BMI. The same result was obtained regarding MCID for back pain severity, where the decrease in BMI (OR $=1.088,95 \% \mathrm{CI}=0.501-2.406)$ or increase in BMI $(\mathrm{OR}=$ $1.004,95 \%$ CI $=0.441-2.336$ ) did not influence long-term outcomes. After adjustment for age and gender, similar values were obtained without relevant changes in the direction or magnitude of the coefficients (all $p>0.05$ ).

\section{Linear regression}

According to a linear regression analysis, there was no association among BMI change and ODI change scores ( $p=$ $\left.0.923, R^{2}=-0.007\right)$. The same result was obtained for NRS leg pain scores $\left(p=0.371, R^{2}=-0.001\right)$, as well as for NRS back pain severity change scores $\left(p=0.385, R^{2}=-0.002\right)$. After adjustment for gender and age, the results were preserved (ODI: $p=0.701$ and $R^{2}=-0.010$; NRS leg pain severity: $p=0.440$ and $R^{2}=-0.002$; NRS back pain: $p=$ 0.438 and $\left.R^{2}=-0.002\right)$.

\section{Discussion}

We analysed 154 patients from a prospective registry who underwent lumbar spine surgery and who had dynamic BMI change data available throughout the preoperative period. A decrease in BMI of $\leq-0.5 \mathrm{~kg} / \mathrm{m}^{2}$ induced a minimal beneficial effect on functional and pain severity improvement, however not by statistical significance. An increase in BMI of $\geq$ $0.5 \mathrm{~kg} / \mathrm{m}^{2}$ also showed no difference in MCID achievement for ODI, as well as for NRS leg pain and NRS back pain. Adjustment for age and gender did not influence results. Similarly, change scores of BMI and PROM change scores demonstrated no association. The hypothesis that dynamic weight loss in the preoperative period increases the benefit of surgery through biopsychosocial interactions is thus not supported by our data.

Overweight patients undergoing lumbar spine surgery are becoming more prevalent year by year [19]. Additionally, obesity has been shown to cause lumbar spinal degenerative disease, such as degenerative disc disease (DDD) with chronic low back pain or facet arthrosis [15, 22]. Therefore, considering body weight and obesity in treatment and prognosis of patients with spinal disorders is more and more a topic of major interest. Understanding the effect of obesity and especially of preoperative weight changes on surgical outcome is important and may pave the way for better decision-makingand thus higher rates of therapeutic success. 
Fig. 1 Distribution of BMI change score. The density plot (curve) demonstrates a nonparametric probability density function smoothed over the patient counts (bins), with the yaxis demonstrating the proportion of patients within these bins. The histogram demonstrates the distribution of patients among the timepoints. BMI, body mass index

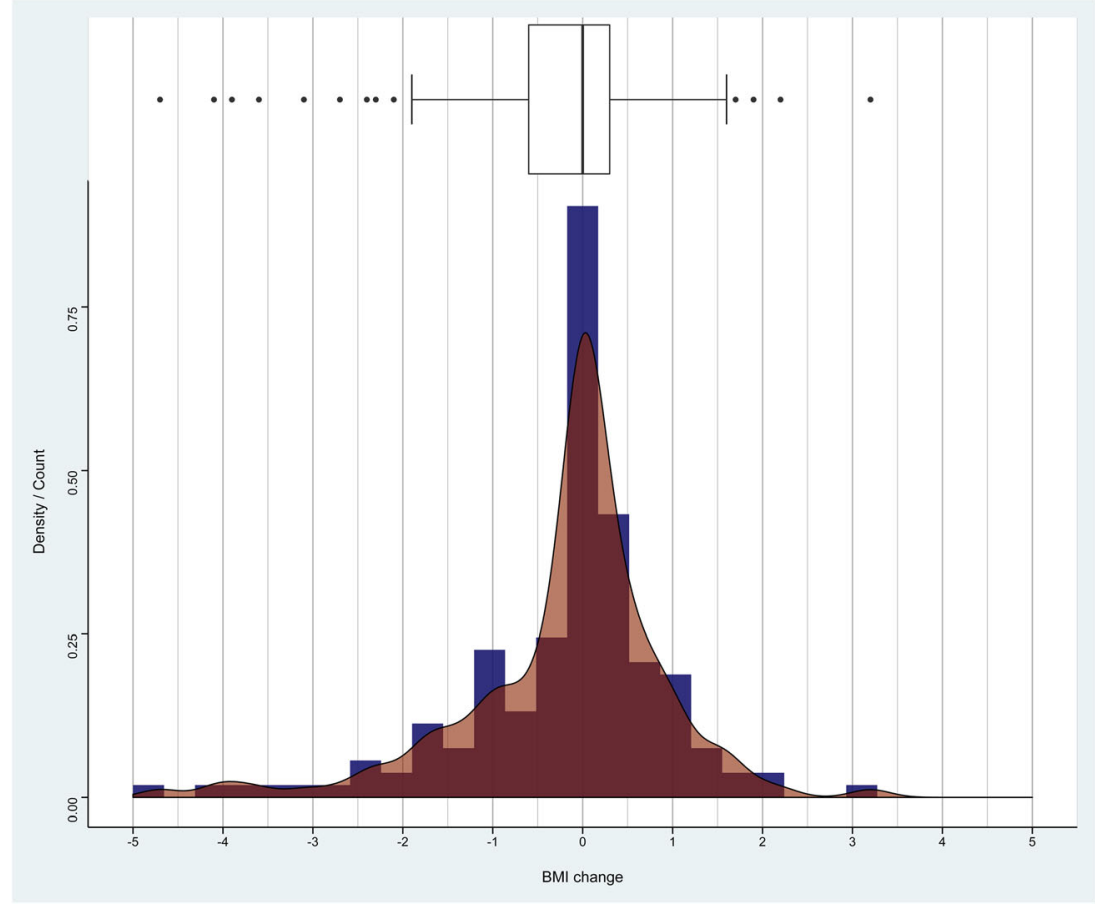

Studies investigating the effect of obesity on surgical outcome mainly show a worse outcome as well as a higher complication rate after surgery [29, 32]. Knutsson et al. [25] were able to show an association of BMI with not only worse surgical outcome but also with a lower level of patient satisfaction. In contradiction, Rihn et al. showed no difference between obese and non-obese patients in terms of postoperative outcome in lumbar discectomy [37]. Onyekwelu et al. also demonstrated that patient-reported outcomes were noninferior for the obese cohort in over 1000 patients undergoing surgery for lumbar spinal stenosis [30]. Thus, the literature on the effect of statically assessed obesity on surgical outcome is still contradictory. As a consequence, obesity should not currently be regarded as a strong negative risk factor for unfavourable

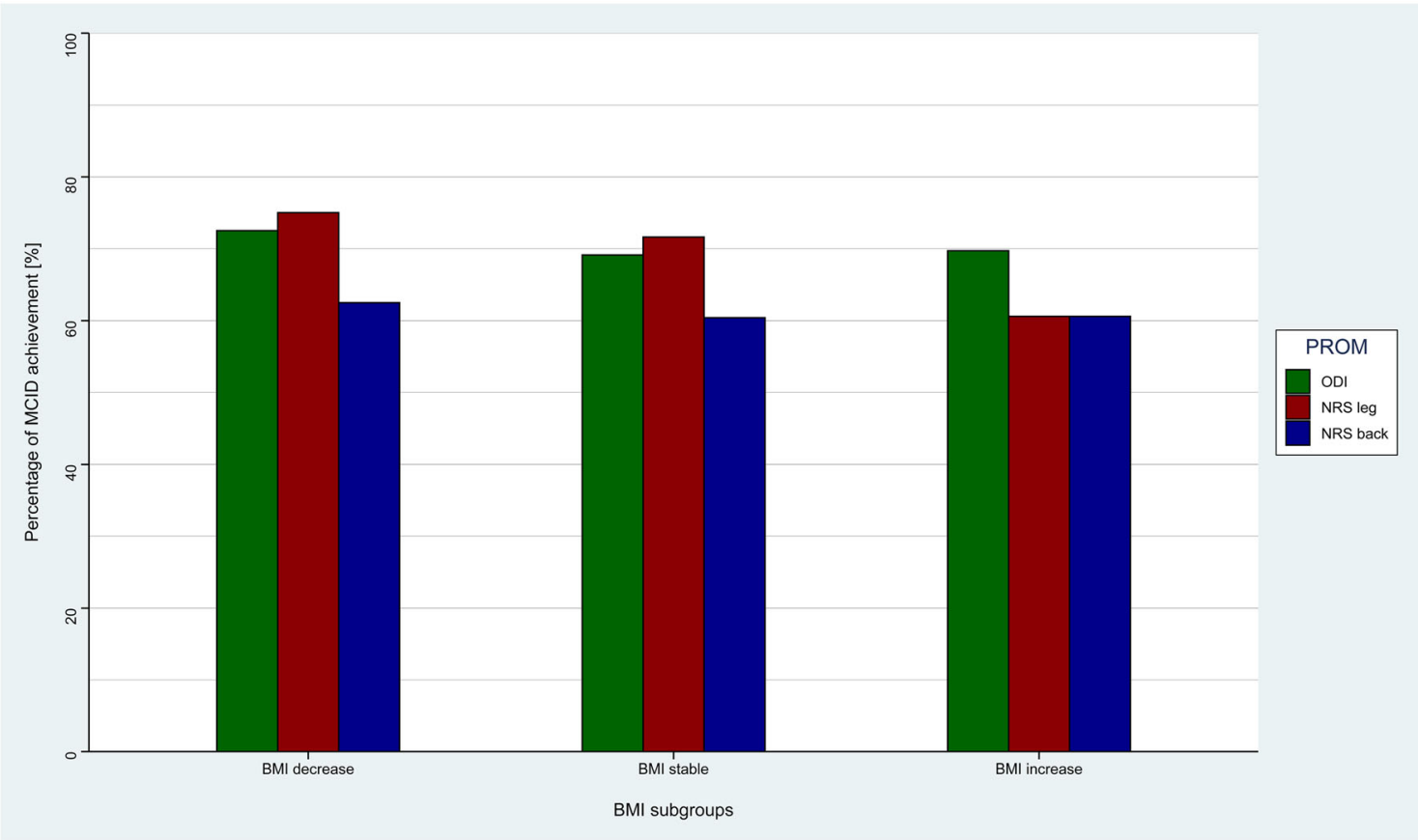

Fig. 2 Distribution of MCID achievement percentages within all BMI subgroups for all 3 PROM values. BMI, body mass index; MCID, minimal clinically important difference; PROM, patient-reported outcome measurement; ODI, Oswestry Disability Index; NRS, numeric rating scale 
Table 2 Logistic regression analysis results of BMI increase or decrease compared to a stable BMI

\begin{tabular}{llll}
\hline Predictor & Odds ratio & CI (95\%) & $p$ value \\
\hline ODI & & & \\
BMI decrease ("weight loss") & 1.18 & $0.52-2.80$ & 0.704 \\
BMI increase ("weight gain") & 1.03 & $0.43-2.55$ & 0.953 \\
NRS leg pain & & & \\
BMI decrease ("weight loss") & 1.19 & $0.51-2.91$ & 0.693 \\
BMI increase ("weight gain") & 0.61 & $0.26-1.44$ & 0.254 \\
NRS back pain & & & \\
BMI decrease ("weight loss") & 1.09 & $0.50-2.41$ & 0.831 \\
BMI increase ("weight gain") & 1.00 & $0.44-2.34$ & 0.991 \\
\hline
\end{tabular}

$* p \leq 0.05$

CI, confidence interval; ODI, Oswestry Disability Index; NRS, numeric rating scale

outcome or even as a contraindication for degenerative lumbar spine surgery $[3,25,29,37]$.

However, clinical hypotheses may arise, linking a potential benefit in surgical outcome and satisfaction with dynamic weight loss - as opposed to static obesity — and concomitant lifestyle changes. It is well demonstrated that psychological factors such as depression and anxiety, as well as positive beliefs about surgery influence patient-reported outcomes after spine surgery $[9,27,28,52]$. These factors may constitute a plausible mechanism that could link any potential effects of weight loss and lifestyle adjustments to patient-reported outcome. Additionally, for any degenerative musculoskeletal disorder, a reduction in mechanical load through weight loss could stimulate less chronic pain development, as has been demonstrated also in the spinal literature [14, 38].

Still, in contrast to static obesity before surgery or weight loss after surgery, there are only few studies investigating the dynamic effect of preoperative weight loss on postoperative surgical outcome, and none in the field of spinal science [6, $20,23]$. A study investigating the effect of preoperative weight loss on total knee arthroplasty outcome in obese patients with a BMI of $\geq 40 \mathrm{~kg} / \mathrm{m}^{2}$ did not state any melioration in physical function improvement after weight loss [23].

Our study however did not show any statistically significant improvements in terms of PROMs related to weight loss. The local insurance restrictions not allowing surgery on obese people with a BMI $>33 \mathrm{~kg} / \mathrm{m}^{2}$ may have weakened any potential beneficial effects of weight loss. Namely, these effects may be far more pronounced with greater or extreme weight loss or with weight loss in patients who are obese and then return to a normal or slightly overweight BMI preoperatively. Therefore, there might be a beneficial effect of preoperative weight loss on morbidly obese patients, while this effect might not be detectable in our patient cohort.
We found slightly but consistently higher odds ratios for MCID achievement in all of the three outcome measures for patients with preoperative weight loss, compared to those with a stable BMI. Nevertheless, the effect was too small to demonstrate statistical significance. Therefore, the presence of a benefit on surgical outcome after preoperative weight loss cannot be robustly ruled out by our findings and may only become statistically apparent in a larger patient cohort with greater statistical power. Even then, though, the effect would be weak. In the end, only a double-blinded randomized controlled trial could robustly identify such effects.

\section{Limitations}

The main limitation of our study is its retrospective nature. Although all events were noted systematically and in a prospective patient registry, and all patients with sufficient data were included in this study, selection bias cannot be ruled out. Additionally, all data stem from a single centre and a single senior surgeon, from which the possibility of centre bias arises. Due to local insurance restrictions, only low-risk patients were allowed to be operated on - thus, those with a BMI $<33$, ASA score 1 or 2, and age up to 80 years - meaning that our findings may not translate to morbidly obese or elderly patients or to patients with severe comorbidities. As discussed above, sample size considerations may constitute an additional limitation of our statistical analysis. We included patients who underwent more minor procedures such as decompression or microdiscectomy, as well as patients undergoing spinal fusion. Our sample size did not allow us to perform a powerful subgroup analysis according to these surgical factors. Also, following patients over a longer preoperative period - which would in turn allow larger weight changes - would certainly have been beneficial. Although most dietary and lifestyle weight loss studies show a significant weight loss after a month or less already, the highest weight loss is usually observed around 3 months into the intervention [41]. We had to opt for a 1-month minimum timespan because, at our centre, patients are usually operated within a few months after the first contact with the surgeon. Thus, we measured a mean time from the first to the last preoperative weight measurement of $121 \pm 98$ days (around 4 months). Lastly, we did not assess any psychological factors such as depression or anxiety, or postoperative weight changes, which could have elucidated the potential underlying mechanisms further.

\section{Conclusions}

In an analysis of a large single-surgeon prospective registry, we found that both preoperative weight loss and weight gain had no measurable effect on long-term postoperative outcome compared to a stable BMI. However, we were unable to look at effects of preoperative weight loss in the morbidly obese 
(BMI > 33) population, as well as the effect of longer-term weight loss. Preoperative weight loss - as a potential surrogate sign of patient motivation and lifestyle change - may thus not influence postoperative outcomes. Further controlled and blinded studies are needed to fully comprehend the effect of weight and weight loss on postoperative outcomes, with higher statistical power and in a multicentre setting.

Funding Open access funding provided by University of Zurich.

Authors' contributions Data collection: MLS, VES. Design: MLS, VES. Analysis: AS. Drafting: AS, VES. Critically reviewed and approved the submitted version: AS, MLS, VES.

Data Availability The raw data will be provided upon reasonable request to the corresponding author.

\section{Compliance with ethical standards}

Conflict of interest The authors declare that they have no conflict of interest.

Ethics approval All procedures performed in studies involving human participants were approved by the regional research committee (MEC-U, W16.065) and with the 1964 Helsinki declaration and its later amendments or comparable ethical standards.

Informed consent Informed consent was obtained from all individual participants included in the study.

Consent to participate Each individual participant signed informed consent to be included in the study.

Consent for publication No individual or identifiable information is provided.

Code availability The statistical code will be provided upon reasonable request to the corresponding author.

Open Access This article is licensed under a Creative Commons Attribution 4.0 International License, which permits use, sharing, adaptation, distribution and reproduction in any medium or format, as long as you give appropriate credit to the original author(s) and the source, provide a link to the Creative Commons licence, and indicate if changes were made. The images or other third party material in this article are included in the article's Creative Commons licence, unless indicated otherwise in a credit line to the material. If material is not included in the article's Creative Commons licence and your intended use is not permitted by statutory regulation or exceeds the permitted use, you will need to obtain permission directly from the copyright holder. To view a copy of this licence, visit http://creativecommons.org/licenses/by/4.0/.

\section{References}

1. Agha M, Agha R (2017) The rising prevalence of obesity: part A: impact on public health. Int J Surg Oncol 2:e17. https://doi.org/10. 1097/IJ9.0000000000000017

2. Anderson PA, Dettori JR, Hermsmeyer JT (2010) Does lumbar decompression in overweight patients assist in postoperative weight loss? Evid Based Spine Care J 1:34-38. https://doi.org/10.1055/s0028-1100912

3. Andreshak TG, An HS, Hall J, Stein B (1997) Lumbar spine surgery in the obese patient. Clin Spine Surg 10:376-379

4. Asher AL, Kerezoudis P, Mummaneni PV, Bisson EF, Glassman SD, Foley KT, Slotkin JR, Potts EA, Shaffrey ME, Shaffrey CI, Coric D, Knightly JJ, Park P, Fu K-M, Devin CJ, Archer KR, Chotai S, Chan AK, Virk MS, Bydon M (2018) Defining the minimum clinically important difference for grade I degenerative lumbar spondylolisthesis: insights from the Quality Outcomes Database. Neurosurg Focus 44:E2. https://doi.org/10.3171/2017. 10.FOCUS17554

5. Bamgbade OA, Rutter TW, Nafiu OO, Dorje P (2007) Postoperative complications in obese and nonobese patients. World J Surg 31:556-560. https://doi.org/10.1007/s00268-0060305-0

6. Benotti PN, Still CD, Craig Wood G, Akmal Y, King H, Arousy HE, Dancea H, Gerhard GS, Petrick A, Strodel W (2009) Preoperative weight loss before bariatric surgery. Arch Surg 144: 1150-1155. https://doi.org/10.1001/archsurg.2009.209

7. Bono OJ, Poorman GW, Foster N, Jalai CM, Horn SR, Oren J, Soroceanu A, Ramachandran S, Purvis TE, Jain D, Vira S, Diebo BG, Line B, Sciubba DM, Protopsaltis TS, Buckland AJ, Errico TJ, Lafage V, Bess S, Passias PG (2018) Body mass index predicts risk of complications in lumbar spine surgery based on surgical invasiveness. Spine J 18:1204-1210. https://doi.org/10.1016/j.spinee. 2017.11.015

8. Buerba RA, Fu MC, Gruskay JA, Long WD, Grauer JN (2014) Obese Class III patients at significantly greater risk of multiple complications after lumbar surgery: an analysis of 10,387 patients in the ACS NSQIP database. Spine J 14:2008-2018. https://doi.org/ 10.1016/j.spinee.2013.11.047

9. Burgstaller JM, Wertli MM, Steurer J, AGH K, Held U, Gramke HF, LSOS Study Group (2017) The influence of pre- and postoperative fear avoidance beliefs on postoperative pain and disability in patients with lumbar spinal stenosis: analysis of the lumbar spinal outcome study (LSOS) data. Spine 42:E425-E432. https://doi.org/ 10.1097/BRS.0000000000001845

10. Byrne TK (2001) Complications of surgery for obesity. Surg Clin North Am 81:1181-1193. https://doi.org/10.1016/S0039-6109(05) 70190-0

11. Chou L, Brady SRE, Urquhart DM, Teichtahl AJ, Cicuttini FM, Pasco JA, Brennan-Olsen SL, Wluka AE (2016) The association between obesity and low back pain and disability is affected by mood disorders. Medicine (Baltimore) 95. https://doi.org/10.1097/ MD.0000000000003367

12. Djurasovic M, Bratcher KR, Glassman SD, Dimar JR, Carreon LY (2008) The effect of obesity on clinical outcomes after lumbar fusion. Spine 33:1789-1792. https://doi.org/10.1097/BRS. 0b013e31817b8f6f

13. Engel GL (1980) The clinical application of the biopsychosocial model. Am J Psychiatry 137:535-544. https://doi.org/10.1176/ajp. 137.5.535

14. Epstein NE (2017) Bariatric bypasses contribute to loss of bone mineral density but reduce axial back pain in morbidly obese patients considering spine surgery. Surg Neurol Int 8:13. https://doi. org/10.4103/2152-7806.198740

15. Fransen M, Woodward M, Norton R, Coggan C, Dawe M, Sheridan N (2002) Risk factors associated with the transition from acute to chronic occupational back pain. Spine 27:92-98

16. Ghoneim MM, O'Hara MW (2016) Depression and postoperative complications: an overview. BMC Surg 16:5. https://doi.org/10. 1186/s12893-016-0120-y

17. Gibson-Smith D, Bot M, Snijder M, Nicolaou M, Derks EM, Stronks K, Brouwer IA, Visser M, Penninx BWJH (2018) The relation between obesity and depressed mood in a multi-ethnic 
population. The HELIUS study. Soc Psychiatry Psychiatr Epidemiol 53:629-638. https://doi.org/10.1007/s00127-018-15123

18. Higgins DM, Mallory GW, Planchard RF, Puffer RC, Ali M, Gates MJ, Clifton WE, Jacob JT, Curry TB, Kor DJ, Fogelson JL, Krauss WE, Clarke MJ (2016) Understanding the impact of obesity on short-term outcomes and in-hospital costs after instrumented spinal fusion. Neurosurgery 78:127-132. https://doi.org/10.1227/NEU. 0000000000001018

19. Hruby A, Hu FB (2015) The epidemiology of obesity: a big picture. PharmacoEconomics 33:673-689. https://doi.org/10.1007/s40273014-0243-X

20. Hutcheon DA, Hale AL, Ewing JA, Miller M, Couto F, Bour ES, Cobb WS, Scott JD (2018) Short-term preoperative weight loss and postoperative outcomes in bariatric surgery. J Am Coll Surg 226: 514-524. https://doi.org/10.1016/j.jamcollsurg.2017.12.032

21. Jackson KL, Devine JG (2016) The effects of obesity on spine surgery: a systematic review of the literature. Global Spine J 6: 394-400. https://doi.org/10.1055/s-0035-1570750

22. Kalichman L, Guermazi A, Li L, Hunter DJ (2009) Association between age, sex, BMI and CT-evaluated spinal degeneration features. J Back Musculoskelet Rehabil 22:189-195. https://doi.org/ 10.3233/BMR-2009-0232

23. Keeney BJ, Austin DC, Jevsevar DS (2019) Preoperative weight loss for morbidly obese patients undergoing total knee arthroplasty: determining the necessary amount. J Bone Joint Surg Am 101: 1440-1450. https://doi.org/10.2106/JBJS.18.01136

24. Khaodhiar L, McCowen KC, Blackburn GL (1999) Obesity and its comorbid conditions. Clin Cornerstone 2:17-31. https://doi.org/10. 1016/S1098-3597(99)90002-9

25. Knutsson B, Michaëlsson K, Sandén B (2013) Obesity is associated with inferior results after surgery for lumbar spinal stenosis: a study of 2633 patients from the Swedish Spine Register. Spine 38:435441. https://doi.org/10.1097/BRS.0b013e318270b243

26. Lidar Z, Behrbalk E, Regev G, Salame K, Keynan O, Schweiger C, Appelbaum L, Levy Y, Keidar A (2012) Intervertebral disc height changes after weight reduction in morbidly obese patients and its effect on quality of life and radicular and low back pain. Spine 37: 1947-1952. https://doi.org/10.1097/BRS.0b013e31825fab16

27. Merrill RK, Zebala LP, Peters C, Qureshi SA, McAnany SJ (2018) Impact of depression on patient-reported outcome measures after lumbar spine decompression. Spine 43:434-439. https://doi.org/10. 1097/BRS.0000000000002329

28. O'Connell C, Azad TD, Mittal V, Vail D, Johnson E, Desai A, Sun E, Ratliff JK, Veeravagu A (2018) Preoperative depression, lumbar fusion, and opioid use: an assessment of postoperative prescription, quality, and economic outcomes. Neurosurg Focus 44:E5. https:// doi.org/10.3171/2017.10.FOCUS17563

29. Omidi-Kashani F, Ghayem Hasankhani E, Rafeemanesh E, Seyf P, Attarchi H, Rahimi MD, Khanzadeh R (2014) Impact of obesity and underweight on surgical outcome of lumbar disc herniation. In: Asian J Neurosci. https://www.hindawi.com/journals/ajn/2014/ 753286/. Accessed 7 Mar 2020

30. Onyekwelu I, Glassman SD, Asher AL, Shaffrey CI, Mummaneni PV, Carreon LY (2017) Impact of obesity on complications and outcomes: a comparison of fusion and nonfusion lumbar spine surgery. J Neurosurg Spine 26:158-162. https://doi.org/10.3171/2016.

31. Ostelo RWJG, Deyo RA, Stratford P, Waddell G, Croft P, Von Korff M, Bouter LM, de Vet HC (2008) Interpreting change scores for pain and functional status in low back pain: towards international consensus regarding minimal important change. Spine 33:90-94. https://doi.org/10.1097/BRS.0b013e31815e3a10

32. Patel N, Bagan B, Vadera S, Maltenfort MG, Deutsch H, Vaccaro AR, Harrop J, Sharan A, Ratliff JK (2007) Obesity and spine surgery: relation to perioperative complications. J Neurosurg Spine 6:291-297. https://doi.org/10.3171/spi.2007.6.4.1

33. Pereira BJA, de Holanda CVM, Ribeiro CAA, de Moura SM, de Carvalho Galvão PE, Quidute BSQ, de Oliveira JG (2014) Impact of body mass index in spinal surgery for degenerative lumbar spine disease. Clin Neurol Neurosurg 127:112-115. https://doi.org/10. 1016/j.clineuro.2014.09.016

34. Pi-Sunyer FX (1999) Comorbidities of overweight and obesity: current evidence and research issues. Med Sci Sports Exerc 31: S602. https://doi.org/10.1097/00005768-199911001-00019

35. Puvanesarajah V, Werner BC, Cancienne JM, Jain A, Pehlivan H, Shimer AL, Singla A, Shen F, Hassanzadeh H (2017) Morbid obesity and lumbar fusion in patients older than 65 years: complications, readmissions, costs, and length of stay. Spine 42:122-127. https://doi.org/10.1097/BRS.0000000000001692

36. R Core Team (2020) R: A language and environment for statistical computing. R Foundation for Statistical Computing, Vienna, Austria

37. Rihn JA, Kurd M, Hilibrand AS, Lurie J, Zhao W, Albert T, Weinstein J (2013) The influence of obesity on the outcome of treatment of lumbar disc herniation. J Bone Joint Surg Am 95:18. https://doi.org/10.2106/JBJS.K.01558

38. Roffey DM, Ashdown LC, Dornan HD, Creech MJ, Dagenais S, Dent RM, Wai EK (2011) Pilot evaluation of a multidisciplinary, medically supervised, nonsurgical weight loss program on the severity of low back pain in obese adults. Spine J 11:197-204. https:// doi.org/10.1016/j.spinee.2011.01.031

39. Schröder ML, de Wispelaere MP, Staartjes VE (2018) Are patientreported outcome measures biased by method of follow-up? Evaluating paper-based and digital follow-up after lumbar fusion surgery. Spine J 19:65-70. https://doi.org/10.1016/j.spinee.2018. 05.002

40. Schröder ML, de Wispelaere MP, Staartjes VE (2019) Predictors of loss of follow-up in a prospective registry: which patients drop out 12 months after lumbar spine surgery? Spine J 19:1672-1679. https://doi.org/10.1016/j.spinee.2019.05.007

41. Shai I, Schwarzfuchs D, Henkin Y, Shahar DR, Witkow S, Greenberg I, Golan R, Fraser D, Bolotin A, Vardi H, TangiRozental O, Zuk-Ramot R, Sarusi B, Brickner D, Schwartz Z, Sheiner E, Marko R, Katorza E, Thiery J, Fiedler GM, Blüher M, Stumvoll M, Stampfer MJ (2008) Weight loss with a low-carbohydrate, Mediterranean, or low-fat diet. N Engl J Med 359:229-241. https://doi.org/10.1056/NEJMoa0708681

42. Shiri R, Karppinen J, Leino-Arjas P, Solovieva S, Viikari-Juntura E (2010) The association between obesity and low back pain: a metaanalysis. Am J Epidemiol 171:135-154. https://doi.org/10.1093/ aje/kwp356

43. Siccoli A, Staartjes VE, de Wispelaere MP, Schröder ML (2018) Is elective degenerative lumbar spine surgery in older adults safe in a short-stay clinic? Data from an institutional registry. Eur Geriatr Med 10:79-88. https://doi.org/10.1007/s41999-018-0132-5

44. Siccoli A, Staartjes VE, de Wispelaere MP, Schröder ML (2018) Gender differences in degenerative spine surgery: Do female patients really fare worse? Eur Spine J 27:2427-2435. https://doi.org/ $10.1007 / \mathrm{s} 00586-018-5737-3$

45. Sinikallio S, Aalto T, Airaksinen O, Herno A, Kröger H, Savolainen S, Turunen V, Viinamäki H (2007) Depression is associated with poorer outcome of lumbar spinal stenosis surgery. Eur Spine J 16:905-912. https://doi.org/10.1007/s00586-007-0349-3

46. Staartjes VE, Siccoli A, de Wispelaere MP, Schröder ML (2019) Patient-reported outcomes unbiased by length of follow-up after lumbar degenerative spine surgery: Do we need 2 years of followup? Spine J 19:637-644. https://doi.org/10.1016/j.spinee.2018.10. 004

47. Staartjes VE, Vergroesen P-PA, Zeilstra DJ, Schröder ML (2018) Identifying subsets of patients with single-level degenerative disc 
disease for lumbar fusion: the value of prognostic tests in surgical decision making. Spine J 18:558-566. https://doi.org/10.1016/j. spinee.2017.08.242

48. Staartjes VE, de Wispelaere MP, Miedema J, Schröder ML (2017) Recurrent lumbar disc herniation after tubular microdiscectomy: analysis of learning curve progression. World Neurosurg 107:2834. https://doi.org/10.1016/j.wneu.2017.07.121

49. Staartjes VE, de Wispelaere MP, Schröder ML (2019) Improving recovery after elective degenerative spine surgery: 5-year experience with an enhanced recovery after surgery (ERAS) protocol. Neurosurg Focus 46:E7. https://doi.org/10.3171/2019.1. FOCUS18646

50. Tetreault L, Wilson JR, Kotter MRN, Nouri A, Côté P, Kopjar B, Arnold PM, Fehlings MG (2016) Predicting the minimum clinically important difference in patients undergoing surgery for the treatment of degenerative cervical myelopathy. Neurosurg Focus 40: E14. https://doi.org/10.3171/2016.3.FOCUS1665

51. Vieli M, Staartjes VE, Eversdjik HAJ, De Wispelaere MP, Oosterhuis JWA, Schröder ML (2019) Safety and efficacy of anterior lumbar interbody fusion for discogenic chronic low back pain in a short-stay setting: data from a prospective registry. Cureus 11: e5332. https://doi.org/10.7759/cureus.5332

52. Wertli MM, Held U, Lis A, Campello M, Weiser S (2018) Both positive and negative beliefs are important in patients with spine pain: findings from the Occupational and Industrial Orthopaedic Center registry. Spine J 18:1463-1474. https://doi.org/10.1016/j. spinee.2017.07.166

53. Zeilstra DJ, Staartjes VE, Schröder ML (2017) Minimally invasive transaxial lumbosacral interbody fusion: a ten year single-centre experience. Int Orthop 41:113-119. https://doi.org/10.1007/ s00264-016-3273-5

54. Zhang T-T, Liu Z, Liu Y-L, Zhao J-J, Liu D-W, Tian Q-B (2018) Obesity as a risk factor for low back pain: a meta-analysis. Clin Spine Surg 31:22-27. https://doi.org/10.1097/BSD. 0000000000000468

Publisher's note Springer Nature remains neutral with regard to jurisdictional claims in published maps and institutional affiliations. 